\section{Conflict and concern}

\section{David Victor}

Energy Policy in the Greenhouse: From Warming Fate to Warming Limit. Volume 1. By F. Krause, W. Bach and J. Kooney. Earthscan, London: 1990. Pp. 224. £29.95.

Global Warming: The Greenpeace Report. Edited by J. Leggett. Oxford University Press: 1990. Pp. 554. Hbk £19.95, pbk£5.95.
RECENT additions to the burgeoning supply of books on global warming have generally offered few novel insights. General readers will find these two new studies of the science and policy issues adequate; experts in the field should recognize virtually all of the arguments. Readers sympathetic to the underlying argument of both studies - that policies should rapidly be set on the risk that climate change will be extreme - will find support for their position in these studies. Critics may be annoyed by the abundance of unsupported statements and speculation.

Despite its title, Energy Policy in the Greenhouse devotes little attention to energy policy. Instead, it is an overview of various issues related to global warming, emissions of greenhouse gases and assorted policy options.

Most other studies follow the tradition tions about energy use, calculate greenhouse-gas emissions and then predict future warming under various possibilities. Refreshingly, Energy Policy takes the opposite approach; the authors start with a conservative "warming limit" from which they compute acceptable patterns of greenhouse-gas emissions.

The other main feature of this study is the integration of geophysical and greenhouse-gas emissions models. Notably, the authors present a persuasive case for examining temperature increases over time - known as the transient climatic response - which they argue should be limited to a tenth of a degree centigrade per decade (a reasonable number based on the rate at which trees can adjust to climate change). Only a few other studies have explicitly linked the transient response of the Earth's climate to energy; as such, this research is innovative.

Unfortunately, the report is poorly integrated. Alternative scenarios that are laboriously developed and analysed early in the volume have little relevance to the policy recommendations which emerge later. In all, I have been able to identify at least 28 distinct possibilities which appear at various points in the study. Especially unfortunate is the lack of continuity between the geophysical modelling and the emissions modelling. Furthermore, innovative consideration of the transient response dissipates after the first third of the book. In the final chapters, the range of scenarios the authors deem acceptable of energy modelling and start with assump- is dominated by static conceptions of warming and does not reflect the limits and opportunities of the transient response.

Throughout the book, the authors posit incisive questions yet answer these queries without analytical rigour. The policy recommendations span a wide range of industrial and agricultural practices, but the report sacrifices depth in its attempt to be comprehensive. (But readers should look forward to volume 2 , currently in preparation, which focuses more sharply on energy policy.)

The Greenpeace Report is a collection of nineteen essays organized around the science, impacts and policy responses related to global warming. Readers will recognize these as the same organizing principles of the three working groups of the United Nations-sponsored Intergovernmental Panel on Climate Change (IPCC) which has been preparing a consensus report on global warming for the past two years. The Greenpeace view of global warming is framed in a critique of the IPCC report.

Greenpeace argues that IPCC has (1) failed to make the risks of climate change apparent, (2) systematically understated the effects of climate change and the risks of extreme change, and (3) failed to recommend stringent measures to slow and reverse global warming. This third attack on IPCC's policy recommendations forms the bulk of the study.

The quality of the Greenpeace Report is uneven. Several of the essays are notable, including those by Birgit Bodlund et al. on Sweden's electricity sector and by Norman Myers on tropical forests (both of which are versions of studies reported elsewhere). Amory Lovins provides his familiar but compelling case for least-cost planning, arguing that it is cheaper to save energy by increasing efficiency than it is to purchase new energy sources. According to the argument, controlling global warming can be profitable.

Some interesting hypotheses emerge from least-cost planning and the data presented by the Greenpeace authors. For example, Bill Keepin repeats his claim that carbon emissions can be reduced at 0.012 tons per dollar invested in energy efficiency, whereas building nuclear plants to offset carbon emissions only displaces 0.002 tons of carbon per dollar. But Myers' numbers suggest that reforestation offsets carbon at an even more efficient 0.75 tons per dollar. Accordingly, every dollar invested in energy efficiency could therefore displace six times the carbon if it were invested in reforestation.

Based on Keepin's data, the concluding chapter of the Greenpeace Report argues that: "Expansion of the nuclear-power industry... would involve diverting funds from cost-effective energy-solutions to the greenhouse crisis ... [and] should have no role to play in the international policy response." Does Greenpeace believe that (considering Myers' data) investments in energy efficiency should have no role in the policy response because they divert funds from reforestation? Presumably the political answer is no, although their economic data may

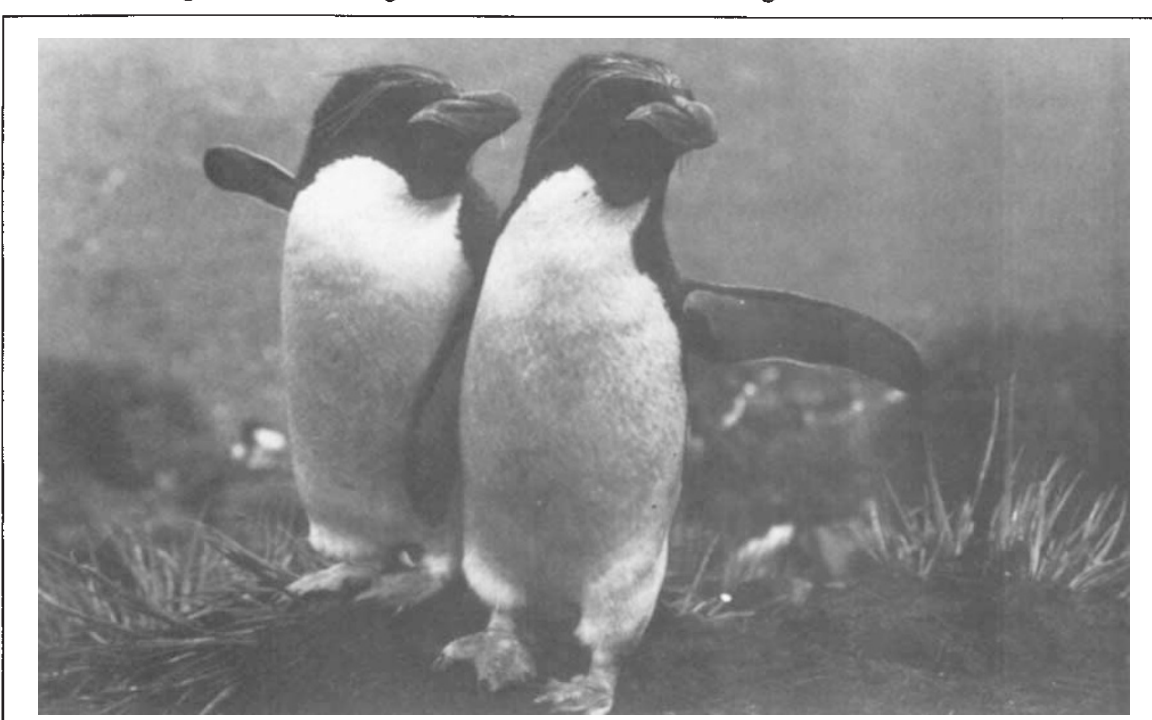

Double greetings - A pair of macaroni penguins on their tussock mound nest site in the Welcome Islands of South Georgia. Wild Ice: Antarctic Journeys by R. Nareen, C. Monteath, $T$. de Roy and $M$. Jones is a desk-top voyage to the Antarctic, illustrated with stunning photos of the wilderness and the birds and animals there. Published by Smithsonian Institution Press, price is $\$ 29.95, £ 19.95$ 